\title{
Numerical investigation on the repeated low-velocity impact behavior of composite laminates
}

\author{
Junjie Zhou ${ }^{\mathrm{a}, \mathrm{b}, *}$, Pihua Wen ${ }^{\mathrm{a}}$, Shengnan Wang ${ }^{\mathrm{b}, *}$ \\ ${ }^{a}$ School of Engineering and Materials Science, Queen Mary University of London, London E1 4NS, UK \\ ${ }^{b}$ School of Aeronautics, Northwestern Polytechnical University, Xi'an 710072, China
}

\begin{abstract}
The dynamic mechanical responses and damage development of cross-ply composite laminates under repeated low-velocity impact are investigated through finite element simulations with ABAQUS/Explicit. A progressive damage model for laminates, consisting of the continuum damage model, the 3D Hashin failure criterion and the damage evolution model based on equivalent displacement, is integrated with the bilinear traction-separation relationship cohesive model to simulate the damage initiation, evolution and propagation behavior of different damage modes in composite laminates. Compared with the experimental results, the established finite element model was validated through the global mechanical response and damage distribution contous. Besides, a mesh refinement study was performed by using three different element sizes. The validated model was adopted to investigate the repeated impact behaviors of composite laminates under three different energies. The qualitative conclusions about the effects of repeated impact on global mechanical response were summarized by the changes of impact force, displacement, contact time and energy absorption. Moreover, the effects of repeated impact on the damage characteristics and expansions of matrix and delamination were discussed in detail.
\end{abstract}

Keywords: Repeated low-velocity impact, impact behavior, damage prediction, damage development, finite element modeling

\section{Introduction}

Composites are the most outstanding materials nowadays due to the high specific stiffness and strength ratio. They are widely applied in various industries, especially in the aerospace industry where most parts of the latest military and civil aircraft structures are made from composites. These composite structures may suffer from repeated impact, such as hail impact and debris impact during their service lives [1, 2]. Although the single low-velocity impact may not cause the external damages, the accumulation of damage created by repeated impact will definitely deteriorate the mechanical properties of the composite structures.

A number of researchers did many experiments to investigate the complicated behaviors of the composite material under repeated low-velocity impact [3, 4, 5, 6, 7]. Considering the low energy in impact process, rupture does not usually occur on a single hit [8]. Actually, a general conclusion obtained is that the multiple impacts will create a clear damaged region, even with a very low energy level. Obviously, it is more important to understand the process of damage development than the energy absorption only. In order to evaluate the repeated impact damages, performing the repeated impacts is the major step, not only in the experiment but also in the numerical simulation.

Compared to the expensive and time-consuming testing, finite element $(\mathrm{FE})$ techniques provide the great opportunity to

\footnotetext{
${ }^{*}$ Corresponding author

Email addresses: junjie.zhou@qmul . ac .uk (Junjie Zhou), wangshna@nwpu.edu.cn (Shengnan Wang)
}

establish a numerical model, which could accurately perform the impact events and predict the complicated behaviors of the composites under repeated low-velocity impact in a relatively short time. The enhanced Schapery theory (EST) [9] can be used as the intra-laminar constitutive model to capture the prepeak and post-peak behavior of a unidirectional lamina, which has been successfully applied to numerical simulation of lowvelocity impact on composites[10, 11, 12, 13]. The progressive damage model (PDM), which considers damage initiation and subsequent stiffness degradation, has become the most popular numerical model to predict the different modes of damage for composites [14, 15, 16, 17, 18, 19, 20, 21, 22, 23, 24]. With regard to determination for damage initiation, the interactive criteria with individual equations to evaluate fiber and matrix damage under tensile and compressive loading have been implemented extensively, such as the Chang-Chang [25], Hou [26, 27], Hashin [28, 29] and Puck[30] criteria. Once the failure criteria are met, a relevant damage evolution model is required to simulate the damage accumulation process around the damaged area. Compared to the constants predefined in a stiffness degradation matrix [31, 32], the equivalent displacement method is preferred by most researchers to describe the loss of stiffness due to the involvement of mechanical parameters [14, 15, 18, 19, 20, 33, 34]. Among the typical damage modes for composites, delamination is regarded as the most significant mode because it may propagate undetectably and result in the unforeseen collapse of the structures [35]. The cohesive zone model (CZM) has been widely used in many previous works [36, 37, 38, 39, 40, 41]. The mixed mode cohesive laws have 
to reduce to the corresponding normal and tangential tractionseparation laws under pure mode loading. Crack propagation was treated by additional conditions imposed at the final crack opening. In this way, one traction component may vanish while the other traction component may not, especially at the boundary of cohesive zone. The incremental mixed-mode evolution law and a novel mixed-mode cohesive formulation proposed by Waas [42, 43] preserves all tractions to vanish simultaneously on the crack plane once the mixed mode final failure criterion is satisfied. The strength-based criterion and fracture energy criterion with the linear softening law are implemented to predict the damage initiation and evolution, respectively. Moreover, the bilinear traction-separation relationship is commonly adopted in the CZM-based interface elements to simulate the delamination of composites[14, 33, 44, 45, 46, 47].

Although numerical simulation is a more timesaving approach, most of the numerical works were mainly aimed at modeling the composite laminates under single impact, instead of repeated impacts. Therefore, the numerical investigation on the composite laminates under repeated low-velocity impact is essential to explore. In this paper, the dynamic mechanical response and damage development of cross-ply composite laminates under repeated low-velocity impact was investigated through the commercial software ABAQUS/Explicit. The progressive damage model for laminates, consisting of the continuum damage model, the 3D Hashin failure criterion and the damage evolution model based on equivalent displacement, was proposed and coded in the user-defined subroutine (VUMAT). The bilinear traction-separation relationship cohesive model was applied to simulate the delamination in composite laminates. The numerical results of single impact were validated and discussed against the experimental results reported by Shi [33]. Moreover, with the help of restart technique in ABAQUS, the repeated impacts were simulated after each single hit. The qualitative conclusions about the effects of repeated impact on global mechanical response were summarized by the changes of impact force, displacement, contact time and energy absorption. In addition, the effects of repeated impact on the damage characteristics and expansions of matrix and delamination were then discussed in detail.

\section{Damage models and formulations}

Generally speaking, composite laminated structures usually show a complicated internal damage pattern which is hard to detect [48]. Fiber and matrix damages and delamination are the main failure modes of composite materials, which can occur internally under low-velocity impact events. Hence, the impact damage prediction can be divided into two parts: (1) Progressive damage model for a lamina; (2) Cohesive zone model for the interface.

\subsection{Progressive damage model}

\subsubsection{Continuum damage model}

Since the composite structures can accumulate damages before collapse, it is incorrect to use the simple failure criterion to predict the ultimate failure. Continuum damage model is more suitable to evaluate the complex progressive failure. The constitutive equation is implemented as follows:

$$
\sigma_{i j}=C_{i j k l} \varepsilon_{k l}
$$

where $\sigma_{i j}, \varepsilon_{k l}$ and $C_{i j k l}(\mathrm{i}, \mathrm{j}, \mathrm{k}, \mathrm{l}=1,2,3)$ denote engineering stress, engineering strain and stiffness matrix components, respectively. The index 1, 2, 3 refers to the fiber direction, in-plane transverse direction and out-of-plane direction, respectively. Due to the fact that each ply in the composite laminates can be considered as a transversely isotropic material, the number of engineering constants $E_{i j}, v_{i j}, G_{i j}$ can be reduced. Only five independent constants remain, which means $E_{22}=E_{33}, v_{12}=v_{13}, G_{12}=G_{13}$. By adding damage variables, the continuum damage model can determine whole range of deterioration in composites, from no damage to complete damage. The degraded compliance matrix $S_{d}$ is expressed as:

$$
S_{d}=\left[\begin{array}{cccccc}
\frac{1}{d_{f} E_{11}} & -\frac{v_{21}}{E_{22}} & -\frac{v_{31}}{E_{33}} & & & \\
-\frac{v_{12}}{E_{11}} & \frac{1}{d_{m} E_{22}} & -\frac{v_{32}}{E_{33}} & & & \\
-\frac{v_{13}}{E_{11}} & -\frac{v_{23}}{E_{22}} & \frac{1}{E_{33}} & \frac{1}{d_{f} d_{m} G_{12}} & & \\
& & & \frac{1}{d_{f} d_{m} G_{23}} & \\
& & & & & \frac{1}{d_{f} d_{m} G_{31}}
\end{array}\right]
$$

where $d_{f}$ and $d_{m}$ denote the fiber and matrix damage variables, respectively. In the meantime, the corresponding degraded stiffness matrix $C_{d}$ is expressed as:

$$
C_{d}=\frac{1}{\Delta}\left[\begin{array}{ccccc}
d_{f} E_{11}\left(1-d_{m} v_{23} v_{32}\right) & d_{f} d_{m} E_{11}\left(v_{21}+v_{23} v_{31}\right) & d_{f} E_{11}\left(v_{31}+d_{m} v_{21} v_{32}\right) & & \\
& d_{m} E_{22}\left(1-d_{f} v_{13} v_{31}\right) & d_{m} E_{22}\left(v_{32}+d_{f} v_{12} v_{31}\right) & & \\
& E_{33}\left(1-d_{f} d_{m} v_{12} v_{21}\right) & & \\
& & \Delta d_{f} d_{m} G_{12} & \\
& & \Delta d_{f} d_{m} G_{23} & \\
& & \Delta d_{f} d_{m} G_{13}
\end{array}\right]
$$




$$
\left\{\begin{array}{l}
d_{f}=\left(1-d_{f t}\right)\left(1-d_{f c}\right) \\
d_{m}=\left(1-S_{m t} d_{m t}\right)\left(1-S_{m c} d_{m c}\right) \\
\Delta=1-d_{f} d_{m} v_{12} v_{21}-d_{m} v_{23} v_{32}-d_{f} v_{13} v_{31}-2 d_{f} d_{m} v_{21} v_{32} v_{13}
\end{array}\right.
$$

where $d_{f t}, d_{f c}, d_{m t}, d_{m c}$ represent the fiber and matrix damage variables of tensile and compressive loads which are calculated by damage evolution model. Besides, the relevant coefficients $S_{m t}$ and $S_{m c}$ are used to control the shear stiffness loss caused by the matrix tension and compression damages [18, 20, 34]. The form of these damage variables is able to reduce the deviation of damage evolution due to the ignorance of plastic deformation for the matrix.

Because of the damage variables inserted in the degraded stiffness matrix in Eq. (3), the numerical calculation will become very difficult to converge. Hence, the Duvaut and Lions regularization model is adopted to smooth the stiffness degradation process [49]. The time derivatives of the damage variables can be expressed as:

$$
\dot{d}_{I}^{v}=\frac{1}{\eta_{I}}\left(d_{I}-d_{I}^{v}\right), \quad I=(f t, f c, m t, m c)
$$

where $\eta_{I}$ and $d_{I}^{v}$ denote viscous parameter and regulated damage variable of failure mode I, respectively. The stiffness reduction of the composites can be realized by substituting the damage variable $d_{I}$ into Eq. (4).

\subsubsection{Failure initiation criterion}

The three-dimensional Hashin criterion [29] is adopted to separately simulate four main failure modes: fiber tensile and compressive failure and matrix tensile and compressive failure, expressed as follows:

Fiber tensile failure $\left(\sigma_{11} \geqslant 0\right)$

$$
F_{f t}=\left(\frac{\sigma_{11}}{X_{T}}\right)^{2}+\alpha\left(\frac{\sigma_{12}}{S_{12}}\right)^{2}+\alpha\left(\frac{\sigma_{13}}{S_{13}}\right)^{2} \geqslant 1
$$

Fiber compressive failure $\left(\sigma_{11}<0\right)$

$$
F_{f c}=\left(\frac{\sigma_{11}}{X_{C}}\right)^{2} \geqslant 1
$$

Matrix tensile failure $\left(\sigma_{22}+\sigma_{33} \geqslant 0\right)$

$$
\begin{aligned}
F_{m t}= & \left(\frac{\sigma_{22}+\sigma_{33}}{Y_{T}}\right)^{2}+\frac{1}{S_{23}^{2}}\left(\sigma_{23}^{2}-\sigma_{22} \sigma_{33}\right)+ \\
& \left(\frac{\sigma_{12}}{S_{12}}\right)^{2}+\left(\frac{\sigma_{13}}{S_{13}}\right)^{2} \geqslant 1
\end{aligned}
$$

Matrix compressive failure $\left(\sigma_{22}+\sigma_{33}<0\right)$

$$
\begin{aligned}
F_{m c}= & \left(\frac{\sigma_{22}+\sigma_{33}}{2 S_{23}}\right)^{2}+\frac{\sigma_{22}+\sigma_{33}}{Y_{C}}\left[\left(\frac{Y_{C}}{2 S_{23}}\right)^{2}-1\right]+ \\
& \frac{1}{S_{23}^{2}}\left(\sigma_{23}^{2}-\sigma_{22} \sigma_{33}\right)+\left(\frac{\sigma_{12}}{S_{12}}\right)^{2}+\left(\frac{\sigma_{13}}{S_{13}}\right)^{2} \geqslant 1
\end{aligned}
$$

where $F_{f t}, F_{f c}, F_{m t}, F_{m c}$ are damage variables of the different damage modes; $\sigma_{i j}(i, j=1,2,3)$ represents the effective stress tensor; $X_{T}$ and $X_{C}$ denote the tensile and compressive strengths in the fiber direction; $Y_{T}$ and $Y_{C}$ denote the tensile and compressive strengths in the transverse direction; $S_{12}, S_{13}$ and $S_{23}$ are the shear strengths.

\subsubsection{Damage evolution model}

After reaching one of the failure initiation criteria, the further loading will lead to the degradation of stiffness constants. Therefore, it is necessary to define the damage evolution model for the composite laminates. The fracture energy-based damage evolution model with equivalent displacement and stress is implemented here.

When the behavior of material becomes softened, the damage shows localizing characteristics because the energy dissipation reduces with mesh refinement. It means that the numerical result is not objective due to the element size. Hence, the crack band model developed by Bažant and Oh [50] was successfully implemented in the damage evolution model to abate the mesh dependence. The energy dissipation in an element can be expressed as:

$$
G_{I}=\frac{1}{2} \sigma_{e q}^{f} \varepsilon_{e q}^{f} l_{c}
$$

where $G_{I}$ denotes the fracture energy density of failure mode $I ; \sigma_{e q}^{f}, \varepsilon_{e q}^{f}$ represent the equivalent peak stress and the equivalent failure strain, respectively; $l_{c}$ indicates the characteristic length of element, which is considered to be equal to the cube root of the element volume in the present work.

The damage variable for each failure mode $I$ can be expressed as:

$$
d_{I}=\frac{\delta_{I, e q}^{f}\left(\delta_{I, e q}-\delta_{I, e q}^{0}\right)}{\delta_{I, e q}\left(\delta_{I, e q}^{f}-\delta_{I, e q}^{0}\right)} \quad\left(d_{I} \in[0,1], I=f t, f c, m t, m c\right)
$$

where $\delta_{I, e q}$ represents the equivalent displacement of the failure mode $I$; the superscripts 0 and $f$ represent the initial damage moment and the final failure moment, respectively. All of them can be calculated by the following formulas:

$$
\begin{aligned}
& \delta_{I, e q}^{f}=\frac{2 G_{I}}{\sigma_{I, e q}^{0}} \\
& \delta_{I, e q}^{0}=\frac{\delta_{I, e q}}{\sqrt{F_{I}}}
\end{aligned}
$$

$$
\sigma_{I, e q}^{0}=\frac{\sigma_{I, e q}}{\sqrt{F_{I}}}
$$

where $F_{I}$ denotes the damage variable of the failure mode $I$; $\sigma_{I, e q}$ represents the equivalent stress of the failure mode $I$. In 
order to calculate the damage variable $d_{I}$ in Eq. $11,, \delta_{I, e q}^{f}$ has to be computed as soon as damage initiates. Hence, the initiation damage equivalent stress $\sigma_{I, e q}^{0}$ is used in Eq. 12 instead of the full damage equivalent stress $\sigma_{I, e q}^{f}$.

The equivalent displacement of the failure mode $I$ was defined by Fang [20] which is associated with the characteristic length of element, fracture energy of the composites constituents, local strain and stress of element. The local strain and stress can be calculated by ABAQUS according to the constitutive equation and material properties. Detailed equations for computing the equivalent displacement and equivalent stress were proposed and displayed in our previous work[14].

\subsection{Cohesive zone model}

Interfacial debonding between the two plies, also known as delamination, has been identified as one of the key damage modes in composite laminates. There are three commonly used models to simulate delamination: failure-criterion based model, fracture mechanics model and cohesive zone model. The first model considers delamination to be one type of failure modes in the failure criteria. For instance, Hou [27] proposed the 3D failure criterion including delamination. ALthough this kind of method does has good numerical efficiency, the interface is not independent due to the inter-reaction between different failure modes. The second model is established based on the virtual crack closure technique (VCCT) [51], which needs to predefine the crack initiation. Besides, this model also requires to apply the adaptive re-meshing technique in the front of crack, which is computationally costly in the three-dimensional problems. However, the last model has overcome the disadvantages of VCCT. The cohesive zone model [36] uses strength-based criterion and fracture energy criterion to describe the damage initiation and evolution.

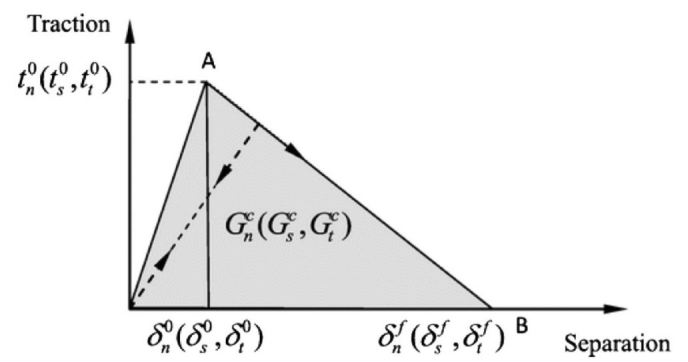

Figure 1: Typical bilinear traction-separation law for cohesive element

Considering the advantages and disadvantages of each models, the zero-thickness cohesive interface elements with the bilinear traction-separation law are inserted in the FE model to simulate delamination between the adjacent plies in the composite laminates. As can bee seen in Fig. 1, the response of cohesive zone elements is controlled by the typical bilinear traction-separation relationship where the subscripts $n, s$ and $t$ are the normal direction, the first and second in-plane shear directions, respectively; the superscripts 0 and $f$ refer to the initial damage moment and the final failure moment, respectively. Before reaching the peak stress, the initial response of cohesive element is assumed to be a linear relationship. If the deformation is purely normal to the interface or in the first or second shear direction, the damage will initiate after point $\mathrm{A}$.

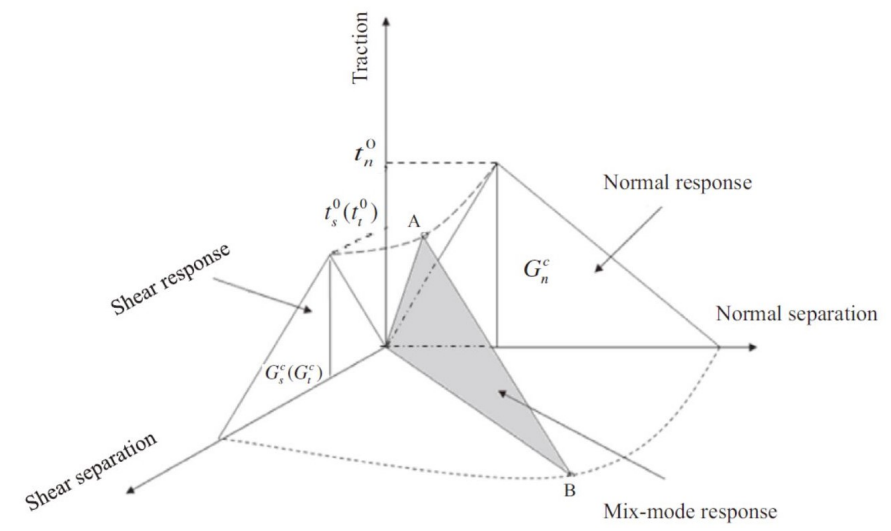

Figure 2: The cohesive zone model under mixed-mode loading

However, the composite structures are always loaded in a mixed mode. Fig 2 illustrates the cohesive zone model under mixed-mode loading, where the shaded triangle represents the mixed-mode response and the two unshaded triangles denote the pure normal and pure shear responses. Points A and B refer to the damage initiation and complete failure of the mixedmode response. Hence, the quadratic failure criterion is adopted to predict the delamination initiation, expressed as follows:

$$
\left(\frac{\left\langle t_{n}\right\rangle}{t_{n}^{0}}\right)^{2}+\left(\frac{\left\langle t_{s}\right\rangle}{t_{s}^{0}}\right)^{2}+\left(\frac{\left\langle t_{t}\right\rangle}{t_{t}^{0}}\right)^{2}=1
$$

where $t_{n}, t_{s}$ and $t_{t}$ represent the normal and shear tractions; $t_{n}^{0}$, $t_{s}^{0}$ and $t_{t}^{0}$ denote the interface normal and shear strengths. Damage is assumed to initiate when a quadratic interaction function involving the nominal stress ratios reaches a value of one. Since the delamination initiates, the damage evolution model with the linear softening law is required. In order to define the damage evolution based on the energy dissipation, the energy dissipated due to failure $G^{C}$ is used as the specification of the nature of the evolution of the damage variable $D$ between damage initiation and final failure. The Benzeggagh and Kenane (B-K) criterion [52] is implemented to calculate the $G^{C}$ under the mixed-mode loading, as follows:

$$
G^{C}=G_{n}^{C}+\left(G_{s}^{C}-G_{n}^{C}\right)\left\{\frac{G_{S}}{G_{T}}\right\}^{\eta}
$$

where $G_{n}^{C}$ and $G_{s}^{C}$ the critical fracture energies in the normal and shear directions, respectively; $G_{S}$ is the energy dissipation in the out-of-plane direction; $G_{T}$ is the total energy dissipation; $\eta$ represents the relevant material coefficient in the B-K formula, which is set to 1.45 in the present study. 


\section{Finite element modeling}

The ABAQUS/Explicit is used to build the numerical finite element model where the failure initiation criterion and damage evolution method described in the earlier section are coded in a VUMAT subroutine. The 3D finite element model based on the experiments performed by Shi[33] is established to analyze the damage characteristics of cross-ply composite laminates under repeated low-velocity impact.

\subsection{Geometric parameters and boundary conditions}

The carbon/epoxy composite laminates with stacking sequences of $[0 / 90]_{2 s}$ are built as a circular plate with a diameter of $75 \mathrm{~mm}$ and a thickness of $2 \mathrm{~mm}$. Local coordinates are defined to account for ply orientations and material behaviors. According to the guidelines given by ASTM D7136/D7136M07 standard[53], the $15 \mathrm{~mm}$ in diameter cylindrical impactor which has a hemispherical head is used in this work, built as an analytical rigid body to avoid deformation. The concentrated masses of $1,1.5$ and $2 \mathrm{~kg}$ and the predefined initial velocity of $3.38 \mathrm{~m} / \mathrm{s}$ in the $\mathrm{z}$-direction are given to the impactor to achieve 7.35, 11.03 and 14.07 $\mathrm{J}$ impact energies. The outer surface of the punch contacts the upper surface of the circular plate with a distance of $0 \mathrm{~mm}$. The $\mathrm{x}$-direction and y-direction of the impactor are constrained so that it can only move along the $\mathrm{z}$ direction. The boundary condition of encastre is implemented in the plate in order to replicate the experimental clamped conditions, as shown in Fig. 3 .

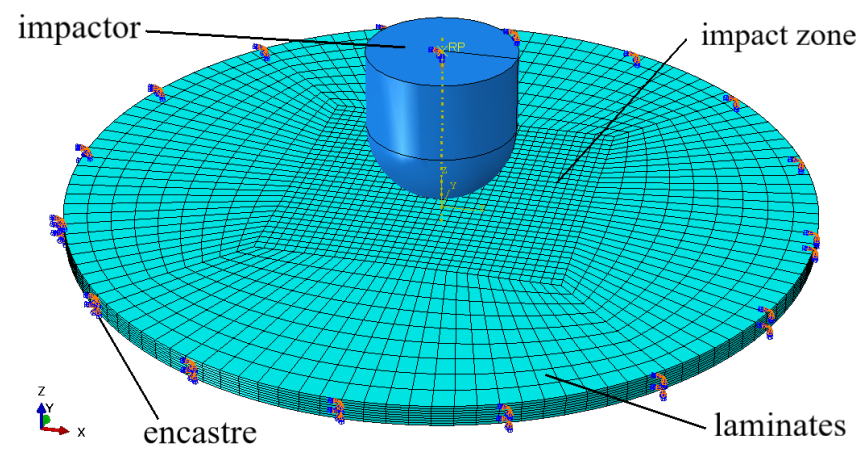

Figure 3: Finite element model of cross-ply carbon/epoxy composite laminates under repeated low-velocity impact

\subsection{Mesh strategy and elements types}

The finite element model is discretized into two regions: the mesh refined inner region (impact zone) and the coarser outer region. A mesh refinement study is performed by using element sizes of $0.8 \mathrm{~mm}, 1.0 \mathrm{~mm}$, and $1.2 \mathrm{~mm}$ in the impact zone under $11.03 \mathrm{~J}$ impact. The impact force-time and force-displacement curves are plotted in Fig. 4.

As the element size decreases, the predicted result becomes more accurate. Although the characteristic length of element is
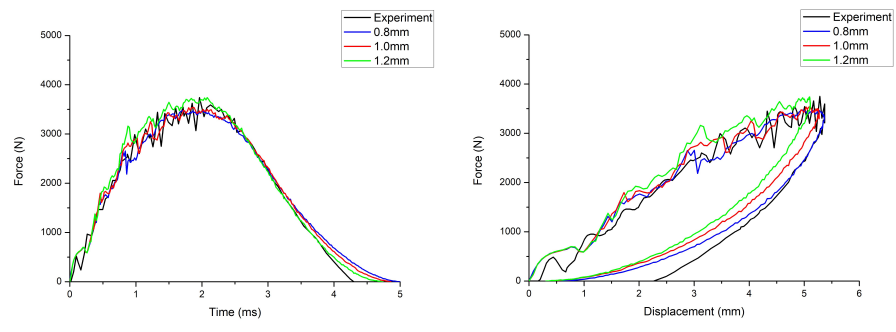

Figure 4: Mesh refinement study

used in the damage evolution model to alleviate mesh dependence, the mesh becomes dependent when elements are damaged and deleted. To achieve a balance between computational efficiency and accurate prediction, the mesh should be fine enough to predict well the dynamic progressive damage of a composite laminate without being too computationally expensive. Hence, the finer mesh with $1 \mathrm{~mm} \times 1 \mathrm{~mm}$ element size is employed in the impact zone whereas the coarser mesh is used in the other regions. The global element size of $2 \mathrm{~mm}$ is implied in FE model to improve computational efficiency. Each layer of the composite laminates is meshed by the eight-node solid element with reduced integration (C3D8R). Considering the hourglass effect, the relax stiffness method is implemented to avoid fake deformation. As regards to the interface, the zerothickness cohesive element is considered to be a better option since it does not affect the geometric thickness of the laminates. The eight-node cohesive elements (COH3D8) are inserted between plys to simulate the delamination. They share the same nodes with adjacent solid elements to ensure continuity of displacement. Once the fiber and matrix tensile damage variables reach the maximum 1 together, the element will be deleted from the mesh in order to consider the possibility of penetration. In a word, the whole mesh is composed of 15840 C3D8R elements and $13860 \mathrm{COH} 3 \mathrm{D} 8$ elements.

\subsection{Contact definition and material properties}

A general contact algorithm in ABAQUS/Explicit is applied to simulate the contact cases in the model. A friction coefficient 0.3 is adopted in the penalty method to describe the tangential behavior. In the meantime, the hard contact method is used to describe the normal behavior. The detailed material properties of composites, including unidirectional lamina and interface, are taken from Refs. [33, 18] and listed in Tabel[1]

\subsection{Numerical analysis process}

The progressive damage model is coded in a usermaterial subroutine VUMAT. The dynamic mechanical response and damage development are conducted by the ABAQUS/Explicit platform with VUMAT. During each incremental step, ABAQUS transfers the current strain increment to the subroutine. Based on the corresponding constitutive model, the stresses and damage states of each layer and interface can be acquired. Once the failure initiation criterion is satisfied, the damage variables will be updated and the degraded stiffness 
Table 1: Material properties for cross-ply carbon/epoxy composite laminates

\begin{tabular}{|c|c|c|}
\hline $\begin{array}{l}\text { Unidirectional } \\
\text { lamina }\end{array}$ & $\begin{array}{l}\text { Strength } \\
\text { properties }\end{array}$ & $\begin{array}{l}1600 \mathrm{~kg} / \mathrm{m}^{3} \\
E_{11}=153 \mathrm{GPa} \\
E_{22}=E_{33}=10.3 \mathrm{GPa} \\
G_{12}=G_{13}=6 \mathrm{GPa} \\
G_{23}=3.7 \mathrm{GPa} \\
v_{12}=v_{13}=0.3 ; v_{23}=0.4 \\
X_{T}=2537 \mathrm{MPa} \\
X_{C}=1580 \mathrm{MPa} \\
Y_{T}=82 \mathrm{MPa} ; \\
Y_{C}=236 \mathrm{MPa} \\
S_{12}=S_{13}=90 \mathrm{MPa} \\
S_{23}=40 \mathrm{MPa} \\
G_{f t}=91.6 \mathrm{~N} / \mathrm{mm} ; \\
G_{f c}=79.9 \mathrm{~N} / \mathrm{mm} ; \\
G_{m t}=0.22 \mathrm{~N} / \mathrm{mm} ; \\
G_{m c}=1.1 \mathrm{~N} / \mathrm{mm}\end{array}$ \\
\hline Interface & $\begin{array}{l}\text { Elastic } \\
\text { modulus } \\
\text { Strength } \\
\text { properties } \\
\text { Fracture } \\
\text { energy } \\
\text { Relevant } \\
\text { coefficient }\end{array}$ & $\begin{array}{l}E_{n}=E_{s}=E_{t}=5 \mathrm{GPa} / \mathrm{mm} \\
N=S=T=30 \mathrm{MPa} \\
G_{n}^{C}=0.6 \mathrm{~N} / \mathrm{mm} ; \\
G_{s}^{C}=2.1 \mathrm{~N} / \mathrm{mm} \\
1.45\end{array}$ \\
\hline
\end{tabular}

matrix will be obtained. With the reduced stiffness matrix updating, the stresses at the integration points of elements will be calculated by ABAQUS/Explicit. At last, the updated state variables are returned to ABAQUS/Explicit and the next increment begins till the end of analysis time. All of these steps constitute the complete process of simulating a single impact.

The repeated low-velocity impact event can be regarded as the combination of multiple single impacts. When the time period in the analysis step reaches the predefined value, it can be considered that the simulation of a single impact process is completed and all result data is stored in the corresponding OBD file. Then, the restart technology in ABAQUS is implemented to import the result of the previous impact as the initial state of the next single impact. In the meantime, the same loading/boundary conditions are implied. At last, the new simulation of repeated impact can be performed according to the procedure of single impact.

\section{Numerical results and discussion}

In the present work, the carbon/epoxy composite laminates are repeatedly impacted by three different energies $(7.35,11.03$ and $14.70 \mathrm{~J}$ ). In order to validate that the established finite element model is suitable for the low-velocity impact of different energies, the numerical results are compared with the experimental data obtained by Shi[33]. In his work, the impact tests of three energies $(7.35,11.03$ and $14.70 \mathrm{~J})$ were performed and the relevant experimental data were reported. Besides, the three values follow a linear relationship, which provides a better comprehension between impact energies and mechanical responses. Hence, the three energies are used as the initial kinetic energy in the numerical analysis. Due to the damage variables and element deletion involving in the numerical model, it is really hard to keep the computation convergent when simulating the relatively higher impact energy. To be more specifically, five impacts of $7.35 \mathrm{~J}$ are simulated to analyze the effect of the number of repeated strikes; the simulations of the second impact at 11.03 and $14.70 \mathrm{~J}$ are performed to study the effect of energy levels on repeated impact. During the process of simulating, the impact force-time, force-displacement and energy-time histories curves are recorded and the different modes of damage contours are displayed.

\subsection{Validation of numerical model}

As shown in Fig. 5, the numerical predictions of global mechanical response are in good agreement with the experimental results. Before reaching the maximum force, the continuous intense oscillations demonstrate that the damages begin to appear in the composite laminates. In the next stage, both the impact force and the displacement reach the maximum. The maximum load is part of the low-velocity impact responses of composites, which is related to the delamination threshold load (DTL) [54]. It is believed that the impact event will not initiate any delamination if the maximum load is below the DTL. After that, the impactor is going to rebound due to the elastic energy of the laminates. It is worth mentioning that the numerical curves take a little more time to return to zero than the experiments did. In the experiment, the displacement measured corresponds to that of the rebounding impactor. With this measurement, when the impactor leaves the surface of the laminates, the laminates may still be curved and does not fully return to a stable state close to zero. As regards to energy absorption, some of the kinetic energy is transformed into the elastic energy of the composite laminates through contact, while the rest of kinetic energy is absorbed by intra-laminar damage, delamination and friction. When the velocity of the impactor reduces to zero, the energy absorption reaches its maximum. In the final stage, the predicted value of energy absorption remains stable, which is always a little lower than the experiment. Fig. 6 provides the delamination contours of $14.70 \mathrm{~J}$ impact energy with no element deletion, where all the damage degrees are represented in rainbow colors. The non-destructive evaluation by penetrant-enhanced X-ray radiography showed an overlapped image of peanut shaped delamination which also looked like two big lobes of delamination in $0^{\circ}$ direction and four small lobes in $0^{\circ}$ and $90^{\circ}$ direction. The predicted distribution of delamination matches well with the X-ray radiograph, except for the slightly larger area. The most severe damages in each interface occur near the central location where the red region is more notable. Fig. 6(c) displays the varying degrees of delamination damage in each interface.

Another numerical simulation is implemented to provide more experimental evidence on delamination by comparing the test data taken from the work of N. Hongkarnjanakul[45]. A T700CG/M21 carbon/epoxy composite laminate with stacking 

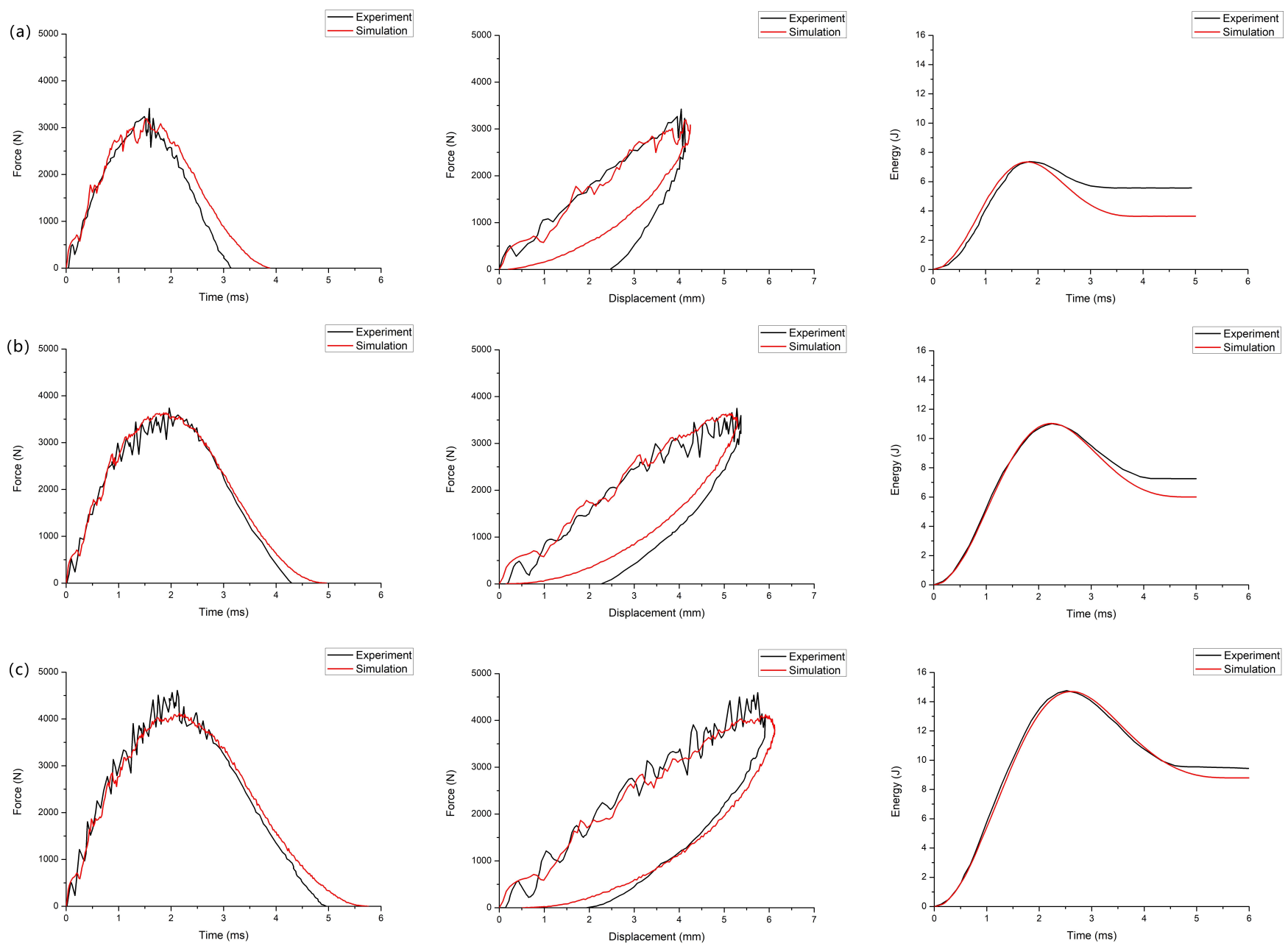

Figure 5: Impact force-time, force-displacement and energy-time curves recorded by experiment and simulation (a) $7.35 \mathrm{~J}$ (b) $11.03 \mathrm{~J}$ (c) $14.70 \mathrm{~J}$

sequences of $\left[0_{2}, 45_{2}, 90_{2},-45_{2}\right]_{S}$ is impacted by $25 \mathrm{~J}$. The geometric size of $150 \times 100 \times 4$ and the clamping boundary condition are established to reproduce the experimental conditions. The detailed material properties for the composites are listed in Table 2. From the Fig. 7, the delamination distribution predicted by numerical method correlates reasonably well with the $\mathrm{C}-\mathrm{Scan}$ result. More specifically, the delamination shape of each layer is basically consistent with the test, except showing the slightly larger areas. Overall, the progressive damage model coded in the VUMAT subroutine and the FE model for low-velocity impact is considered to be verified under different impact energies. The numerical model showed a good capability of predicting the dynamic progressive damage of a composite laminate under low-velocity impact, which could be used in the qualitative analysis on the repeated impact.

\subsection{Effect of repeated impact on global mechanical responses}

Fig. 8 demonstrates the predicted force-time curves of three different energies under repeated impact. Obviously, the three curves of impact force-time histories have common aspects. The curves from the first impact are always characterized by stronger oscillations before reaching the peak value. These
Table 2: Material properties for T700CG/M21 composite laminates

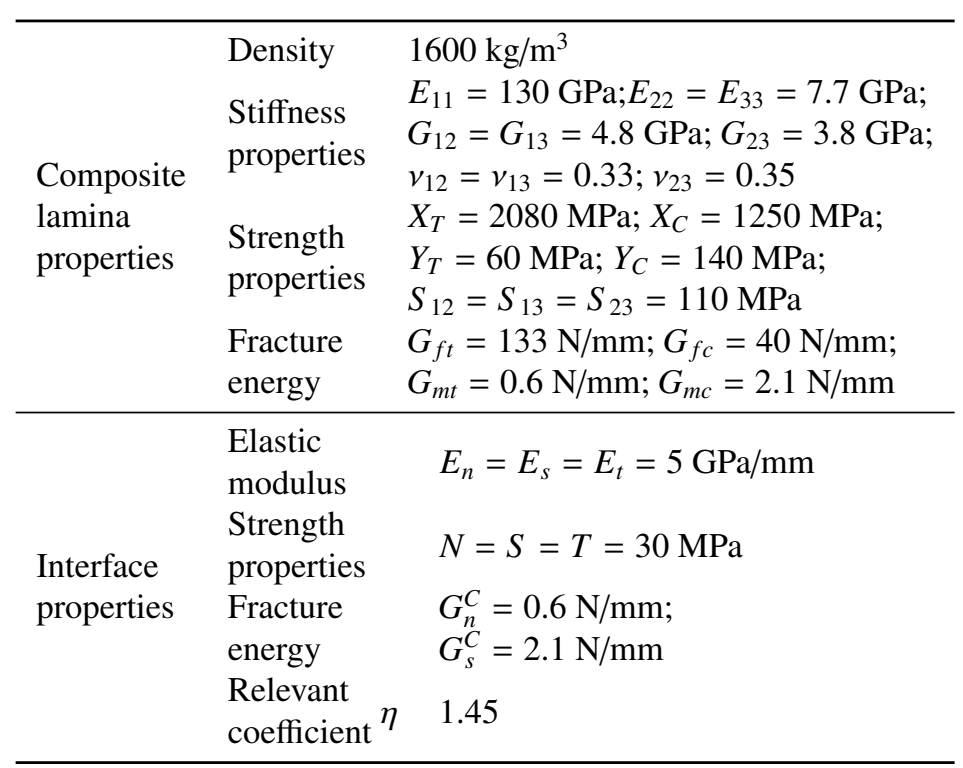




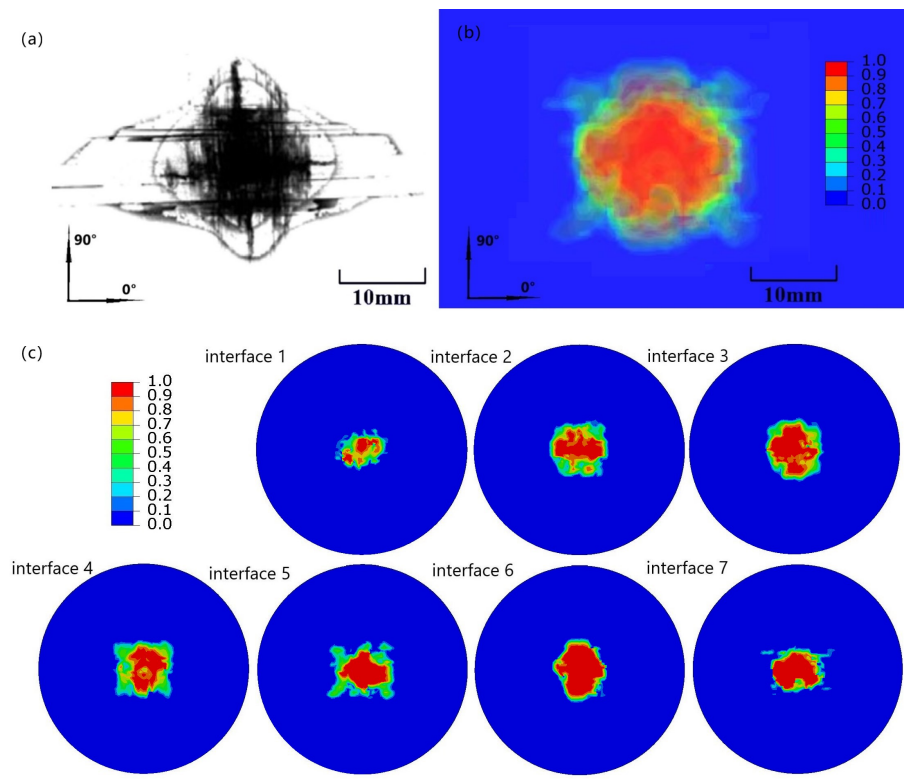

Figure 6: Delamination area of the cross-ply composite laminates under $14.70 \mathrm{~J}$ impact (a) X-ray radiograph (b) Predicted overlapped graph (c) Predicted each interface delamination without element deletion

(a)

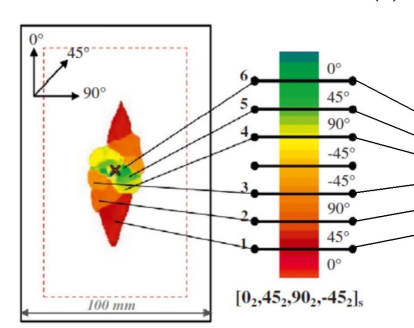

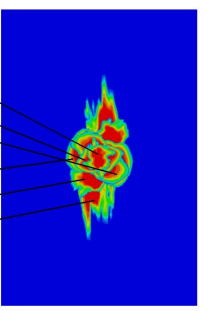

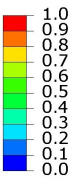

Figure 7: Delamination distribution of the T700CG/M21 composite laminates under $25 \mathrm{~J}$ impact (a) Experimental C-scan result (b) Overlapped graph of numerical result

strong oscillations of the first impact reflect the initiation of damage inside the laminates. On the contrary, the second impact force basically continues to rise without vibration at the same period, which means that the force-time curve of the second impact has hardly any oscillation until approaching the maximum value. The attenuation of oscillation under repeated impact is due to scattering phenomena of the elastic waves, such as wave reflection at newly created damages inside the material and wave interactions [55]. From the second impact, as shown in Fig. 8 (a), the peak force decreases slightly with the increase in the number of impacts, which can be considered that the repeated impact force remains substantially stable before penetration. Besides, the maximum force of repeated impact is greater than that of single impact, which is consistent with the experimental conclusions obtained by Shen [56]. Shen found that the increase in peak force of the impact force history during the repeated impact was unexpected since the initiation of delamination in the first impact would reduce the stiffness of composites, which should result in a decrease rather than an increase in the maximum force during the repeated impact under the same im-
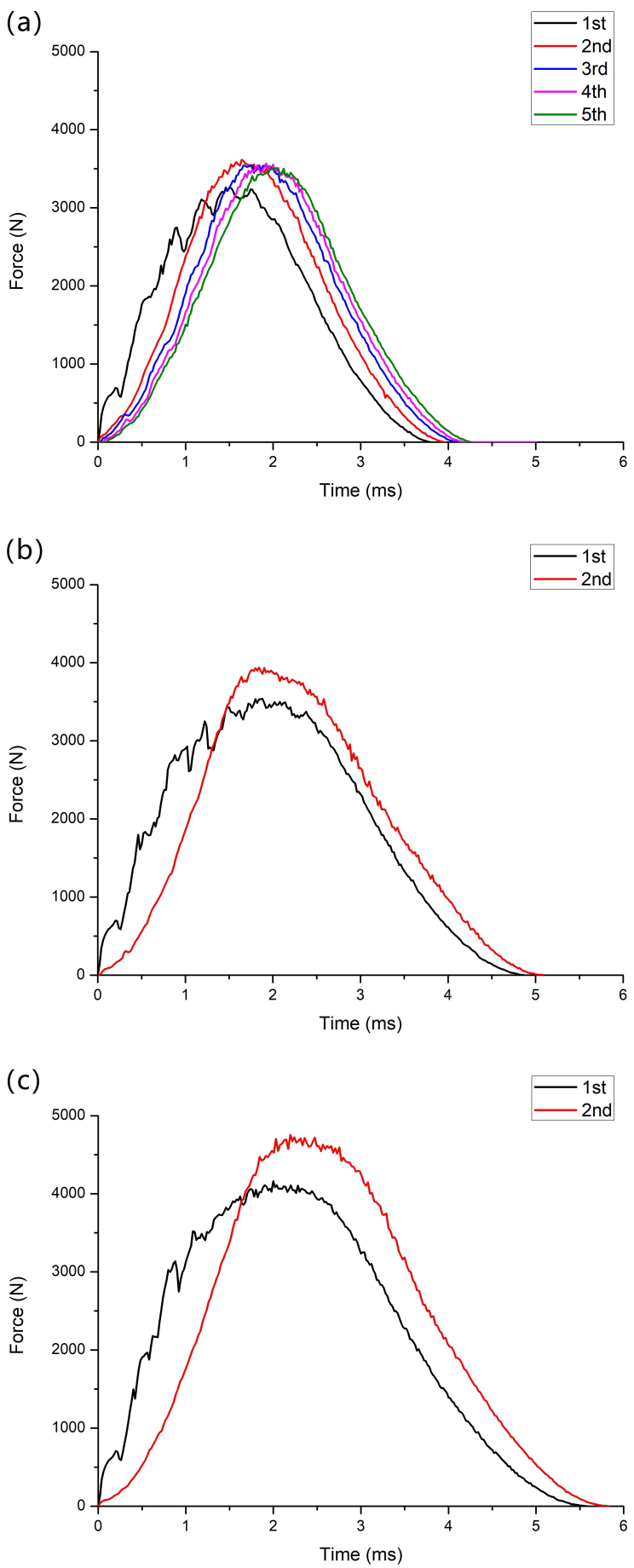

Figure 8: Predicted repeated impact force-time histories of three impact energy levels (a) $7.35 \mathrm{~J}$ (b) $11.03 \mathrm{~J}$ (c) $14.70 \mathrm{~J}$

pact energy level. After reaching the peak force, the impactor is going to rebound. As long as the impactor contacts the laminates, the force exists and is not zero. Due to more serious damage created by the repeated impact, the impactor goes further in the thickness direction, which means that the impactor will need more time to bounce off the laminates. Therefore, the force of the repeated impact takes more time to zero than that 

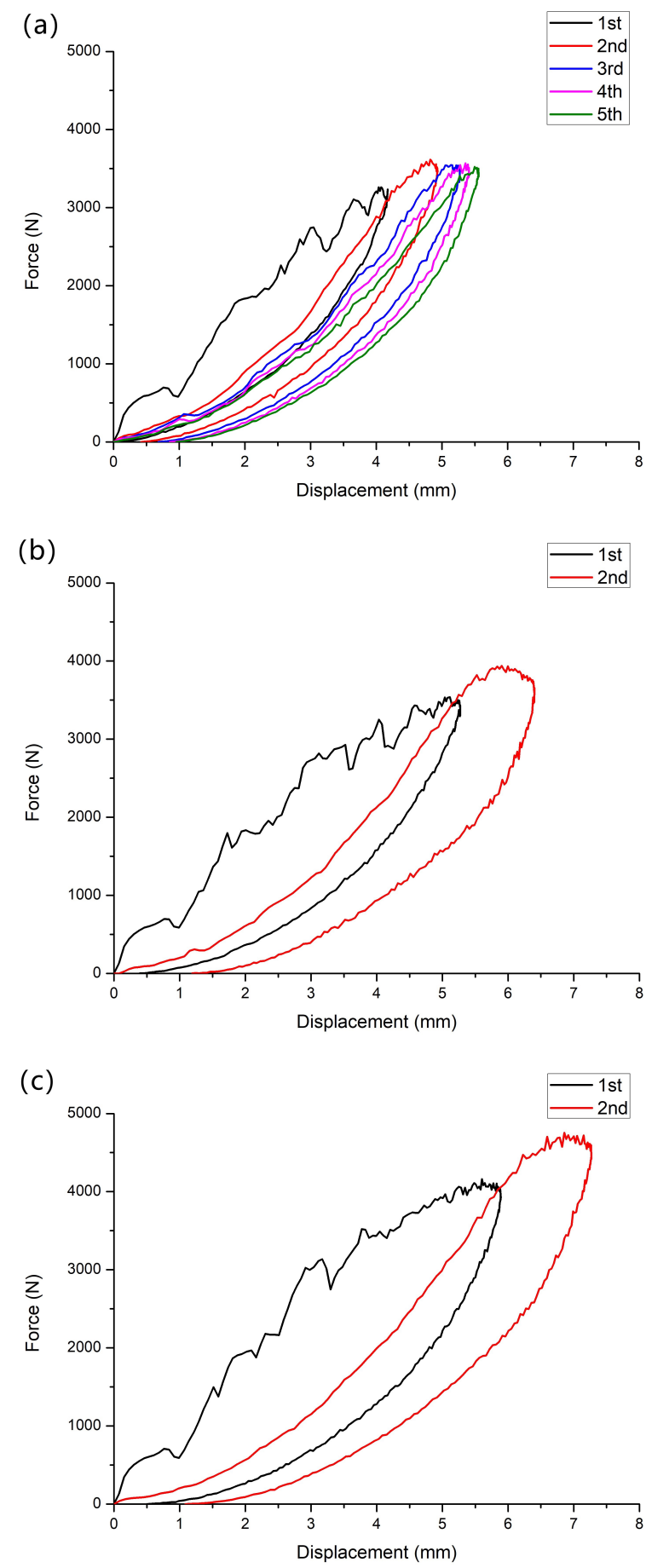

Figure 9: Predicted repeated impact force-displacement histories of three impact energy levels (a) $7.35 \mathrm{~J} \mathrm{(b)} 11.03 \mathrm{~J}$ (c) $14.70 \mathrm{~J}$

of the first impact. The higher the impact energy, the longer the contact time, which leads to more serious damage in the composite. Moreover, the longer contact time in the repeated impact is expected with the increase in the number of strikes. Since the laminates are more damaged in the repeated impact, the damaged plate deflects more, which results in increasing the contact time between the impactor and the composites.
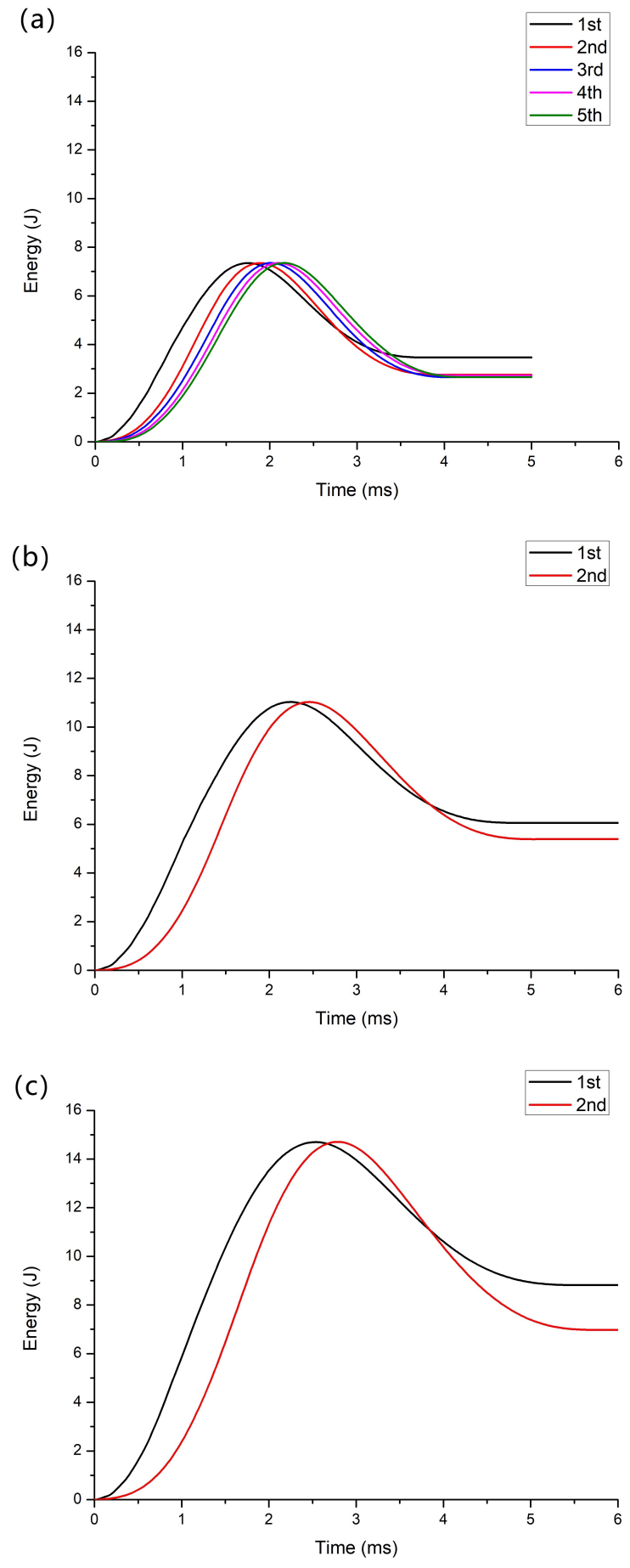

Figure 10: Predicted repeated impact energy-time histories of three impact energy levels (a) $7.35 \mathrm{~J}$ (b) $11.03 \mathrm{~J}$ (c) $14.70 \mathrm{~J}$

Fig. 9 indicates the repeated impact force-displacement curves of three impact energy levels. As can be seen, a similar trend for repeated impact is observed in the three energies. The maximum displacement of second impact is always larger than the first, which is also expected due to more damages. Comparing the Fig. $9(\mathrm{a}-\mathrm{c})$, the deflection increment of repeated impact increases with rising the impact energy. Like the single 
impact event, when the load reaches the peak value, the displacement also approaches the maximum. Fig. 9 (a) reveals that the increment of the maximum displacement gradually decreases with increasing the number of strikes. When the force returns to zero, the final displacement not only grows as the impact energy increases, but also increases with the number of impacts.

Fig. 10 demonstrates the repeated impact energy-time curves of three impact energy levels. The initial kinetic energy of the impactor starts to transfer to the laminates as soon as the contact occurs. Some of the kinetic energy is absorbed by deformation, and the other part is dissipated by the damage, friction and vibration of the plate. When the velocity of the impactor reduces to zero, the energy absorption reaches its maximum, which means that the kinetic energy is completely transfered to the composite plate. It is worth noting that the moment when the laminates absorbs the maximum energy is delayed with increasing the number of impacts. After that, the elastic energy of the plate drives the impactor to rebound. In the last phase, the energy absorption reaches a stable value due to the damage, friction and deformation. With impact energy increasing, the composites absorb more energy, which means that the damage situation becomes more serious in higher energy levels. In regard to the repeated impact, it is obviously that the energy absorption is less than the first impact due to the existing damages in the composites. As shown in Fig. 10 (a), the energy absorption decreases from $3.47 \mathrm{~J}$ in the first impact to approximately $2.8 \mathrm{~J}$ in the repeated impact. The case of $14.70 \mathrm{~J}$ reduces the energy absorption most, from $8.82 \mathrm{~J}$ to $6.98 \mathrm{~J}$. One of the reasons for this phenomenon may be the deformation of the laminates. The deformation caused by the first strike to the intact plate is larger than that by the repeated impacts to the damaged plate. Another reason is that the first impact causes damages in the laminates, leading to the reduction of stiffness. Since the elements in the impact zone are damaged, the laminates absorb less energy in the second impact. In addition, the energy absorption of the subsequent repeated impacts is basically equal to the result of the second impact. The reason for this may be that during the first impact, the damaged elements in the impact zone have reached the limit of degradation so that the subsequent impacts will have little effect on energy absorption.

\subsection{Effect of repeated impact on matrix damage evolution}

Fig. 11 (a-c) demonstrate the predicted matrix tensile damage evolution in the top and bottom layers under different impact energy levels. The red area represents the regions where the damage variable reaches the value of one, while the blue area represents undamaged regions defined for all contours in this study. The damage variable for each failure mode is defined as the solution-dependent state variable (SDV) in the VUMAT subroutine. Hence, the result of a particular failure mode is displayed when the corresponding SDV is chosen in the visualization module of ABAQUS. It is worth noting that some elements are removed by the deletion control in some cases, which means that these regions meet the matrix tensile failure as well as fiber tensile failure at the same time. As can be seen, the tensile damage in each ply occurs around the center of the lamina,
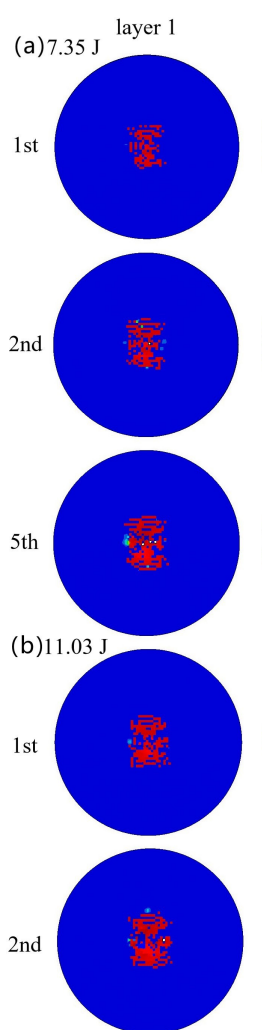

(c) $14.70 \mathrm{~J}$

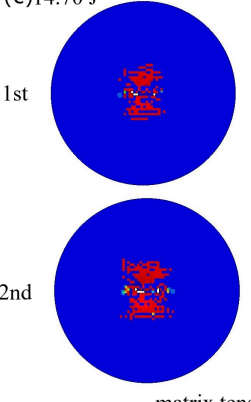

matrix tensile damage
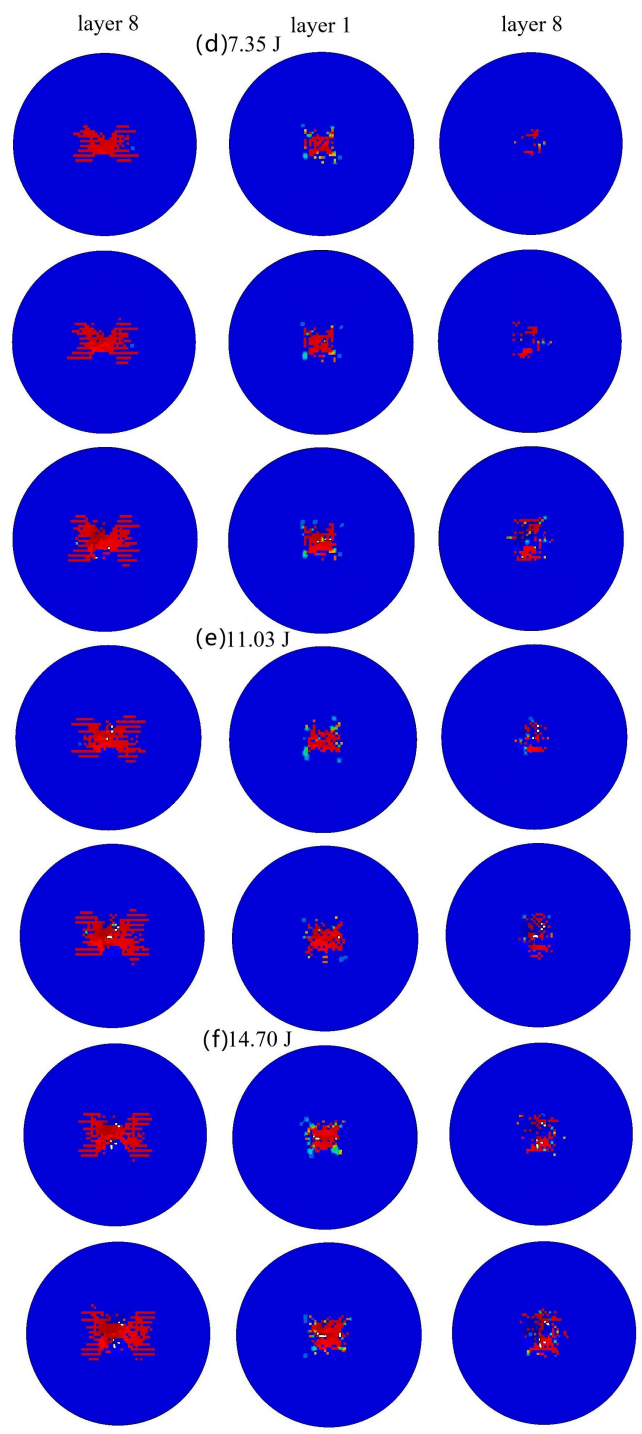

matrix compressive damage

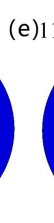

Figure 11: Predicted matrix damage development in typical layers of the crossply composite laminates under repeated impact (a-c) Matrix tensile damage (d-f) Matrix compressive damage

extending mainly along the fiber direction. The repeated impact does not produce as much damage as the first impact but causes the damage to develop slightly along the fiber direction with a little new damage appearing in the direction perpendicular to the fiber. Comparing the Fig. 11 (a-c), the predicted matrix tensile damage areas in the two plies become larger as the impact energy and the number of impacts increase. What stands out in the graphs is that the damage areas of the second impact under $7.35 \mathrm{~J}$ are still less than those of the first impact under 14.70 $\mathrm{J}$ though they are subjected to the same total energy impact. Furthermore, the damage area in the last layer extents more than the first layer under repeated impact. This finding may be interpreted by the fact that the matrix tensile damage initiates on the back side of the laminates and gradually expands to the upper plies [57]. With respect to the damage shape, the bottom $0^{\circ}$ layer looks like a capital letter $X$, while the top $0^{\circ}$ 


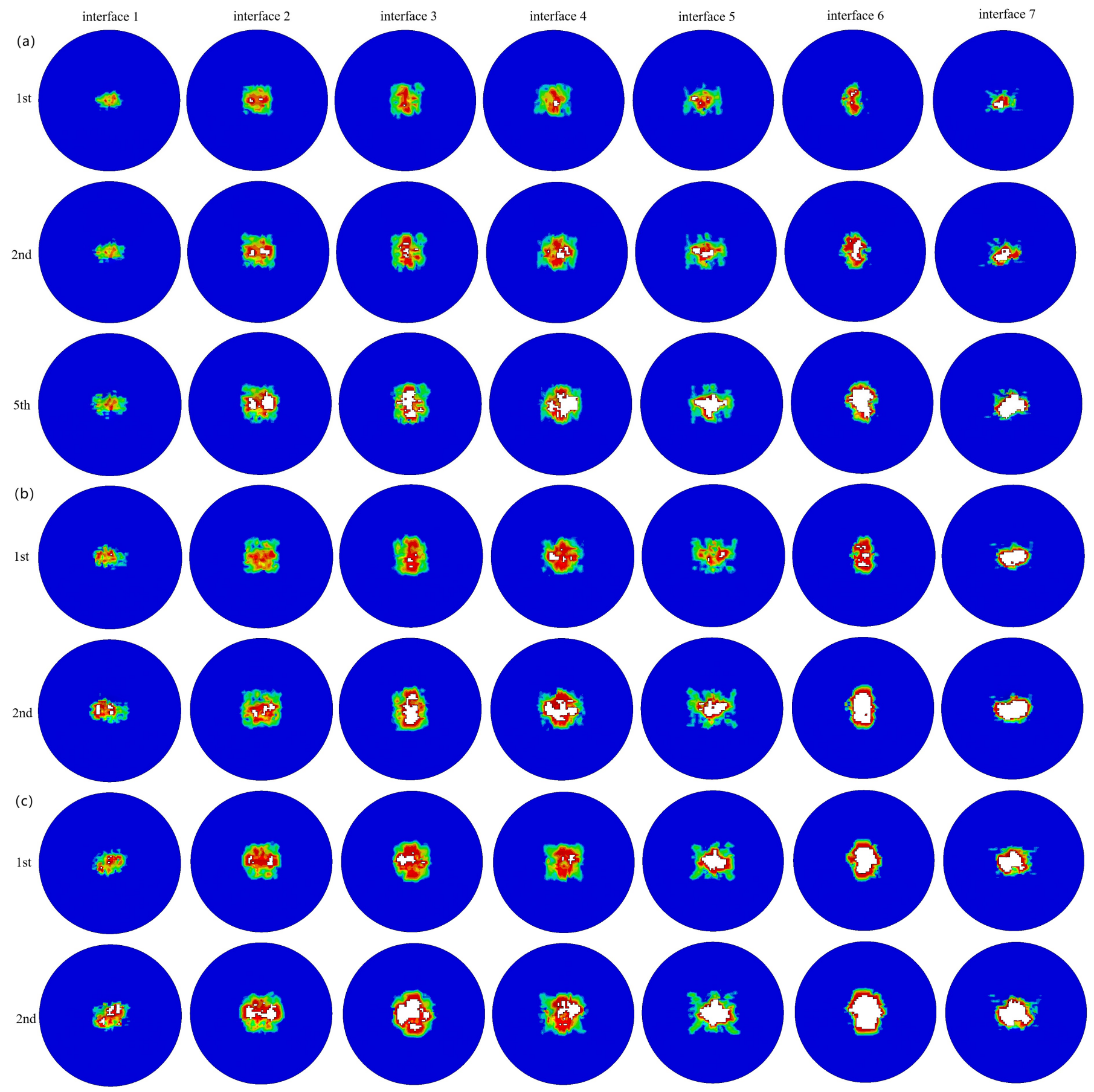

Figure 12: Predicted delamination area in each interface of the cross-ply composite laminates under repeated impact (a) $7.35 \mathrm{~J}$ (b) $11.03 \mathrm{~J}$ (c) $14.70 \mathrm{~J}$

layer looks like a rectangular with the long side perpendicular to the fiber orientation. Repeating the impact does not fundamentally change the shape of the matrix tensile damage, but only increases the area.

Fig. 11(d-f) illustrate the development of predicted matrix compressive damage in typical plies under repeated impact. Obviously, the compressive damage area is significantly less than the tensile damage area, especially in the Fig. 11.d). Considering the impact energy levels, the greater the impact energy, the larger the damaged area. It is worth mentioning that the last layer has less damage than the first layer under the single impact. This phenomenon can be explained that the matrix compressive damage occurs first on the impact side and propagates downward to the back side, so that the compressive damage at the top ply is much more severe than that at the bottom ply. However, the damaged area of the last ply is affected more by the repeated impact and becomes larger with increasing the impact energy, while the repeated impact has the fewer effects on 


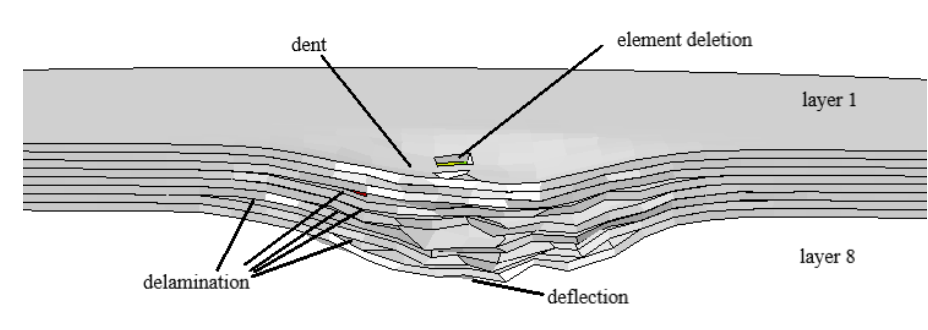

Figure 13: View of lateral side of numerical model after five times $7.35 \mathrm{~J}$ impacts

compressive damage in the top ply. In Fig. 11.d), the fifth impact leaves a large damaged area in the bottom layer, which is far greater than the first impact does. In the meantime, the damaged area in the top layer spreads inapparently as the number of impacts increases. Compared the two $7.35 \mathrm{~J}$ impacts with the single $14.70 \mathrm{~J}$ impact, although the laminates eventually suffer the same energy, the compressive damage areas of the second impact under 7.35 $\mathrm{J}$ are still less than those of the first impact under $14.70 \mathrm{~J}$, just like the results of tensile damage. As for the damage pattern, the damaged area is created around the impact zone in the first layer, expanding slightly to the surroundings with increasing the number of impacts. On the contrary, there is a little undamaged spot at the center of the last layer, even under repeated impact. Considering the orientation of fiber, the matrix compressive damage does not extend along the fiber orientation but concentrates on the damaged area created by the first impact and propagates slightly in all directions as the number of impacts increases.

\subsection{Analysis of delamination development under repeated im- pact}

The predicted delamination area in each interface of the cross-ply composite laminates under repeated impact are displayed in Fig. 12 The delamination starts on the bottom side due to the deflection. During the impact process, larger deformation and matrix damages cause more delamination propagating along the thickness direction to the impacted side. The element will be removed from the mesh when the damage variable of delamination reaches the value of one. The deleted area which is the white area shown in Fig. 12 represents the complete delamination. It is clear that the interfaces near the back have more elements removed than these near the top. In other words, the delamination propagates from the bottom up with each impact. In the top interface, the most parts of damage area are partial failure colored green, while a few completely failed elements are found in the case of relatively higher energy. Moreover, the delamination in the last two interfaces are basically completely failed where more elements near the center are removed. Comparing the results of the second impact under three energies, the damaged areas becomes larger and more failed elements are found in the several layers near the impact surface as the impact energy increases, which is consistent with the conclusions of the single impact. As can be seen from the Fig. 12(a), the repeated impact has less effects on the top interface where no failed elements are found even impacted five times. Focusing on the other interfaces, the damaged areas extend slightly along the fiber orientation of the lamina below the corresponding interface and more elements are removed near the center of each interface. After the fifth impact, the delamination of the laminates is very serious except for the first layer. Comparing the results of the second impact of $7.35 \mathrm{~J}$ with the first impact of $14.70 \mathrm{~J}$, it can be concluded that although the final impact energy is the same, the delamination of repeated lower energy impact is not as serious as the single higher energy impact. Fig. 13 indicates the view of lateral side of numerical model after five times $7.35 \mathrm{~J}$ impacts, where delamination and element deletion can be found easily.

\section{Conclusion}

In this paper, the dynamic mechanical responses and damage development of cross-ply composite laminates under repeated low-velocity impact are investigated through ABAQUS/Explicit with a user-material subroutine VUMAT. The paper is aimed to provide a useful reference for understanding the repeated impact response of the cross-ply composite laminates. A progressive damage model which consists of the continuum damage model, the 3D Hashin failure criterion and the damage evolution model based on equivalent displacement is integrated with the bilinear traction-separation relationship cohesive model to simulate the damage initiation, evolution and propagation behaviors of the composites. Some qualitative conclusions of repeated impact on the cross-ply composite laminates are obtained as follows:

- The second impact increases the peak impact force in all three impact energy levels. But the following impacts do not affect the maximum value which remains stable with the second impact before penetration.

- The maximum displacement and contact time raise gradually as the number of impacts increases.

- The laminates absorb less energy in the second impact than the first, and the energy absorption of the following repeated impacts is equal to the result of the second impact.

- With regard to matrix tensile damage, the repeated impact does not produce as much damage as the first impact but causes the damage to develop slightly along the fiber direction with a little new damage appearing in the direction perpendicular to the fiber orientation.

- The matrix compressive damage does not extend along the fiber orientation but concentrates on the damaged area created by the first impact and propagates slightly in all directions as the number of impacts increases.

- The delamination occurs near the center of each interface and propagates from the bottom up with each impact. The damaged area expands slightly along the fiber direction of the lamina below the corresponding interface as the number of impacts increases. Besides, the repeated impact affects the top interface less than the other interfaces. 


\section{Acknowledgment}

Zhou thanks his sponsor (China Scholarship Council) for supporting his study at Queen Mary University of London where this work was done.

\section{References}

[1] R. Bogenfeld, J. Kreikemeier, T. Wille, Review and benchmark study on the analysis of low-velocity impact on composite laminates, Engineering Failure Analysis 86 (2018) 72-99.

[2] P. F. Liu, J. Y. Zheng, Recent developments on damage modeling and finite element analysis for composite laminates: A review, Materials \& Design 31 (8) (2010) 3825-3834.

[3] G. Rajkumar, M. Krishna, H. Murthy, S. Sharma, K. Mahesh, Investigation of repeated low velocity impact behaviour of gfrp/aluminium and cfrp/aluminium laminates, International Journal of Soft Computing and Engineering 1 (6) (2012) 50-58.

[4] O. S. David-West, D. H. Nash, W. M. Banks, An experimental study of damage accumulation in balanced cfrp laminates due to repeated impact, Composite Structures 83 (3) (2008) 247-258.

[5] J. Aurrekoetxea, M. Sarrionandia, M. Mateos, L. Aretxabaleta, Repeated low energy impact behaviour of self-reinforced polypropylene composites, Polymer Testing 30 (2) (2011) 216-221.

[6] G. R. Rajkumar, M. Krishna, H. N. Narasimha Murthy, S. C. Sharma, K. R. Vishnu Mahesh, Experimental investigation of low-velocity repeated impacts on glass fiber metal composites, Journal of Materials Engineering and Performance 21 (7) (2011) 1485-1490.

[7] F. Morinière, R. Alderliesten, M. Tooski, R. Benedictus, Damage evolution in glare fibre-metal laminate under repeated low-velocity impact tests, Open Engineering 2 (4) (2012).

[8] W. A. de Morais, S.N.Monteiro, J. R. M. d'Almeida, Effect of the laminate thickness on the composite strength to repeated low energy impacts, Composite Structures 70 (2) (2005) 223-228.

[9] E. J. Pineda, A. M. Waas, Numerical implementation of a multiple-isv thermodynamically-based work potential theory for modeling progressive damage and failure in fiber-reinforced laminates, International Journal of Fracture 182 (1) (2013) 93-122.

[10] S. I. Thorsson, A. M. Waas, M. Rassaian, Numerical investigation of composite laminates subject to low-velocity edge-on impact and compression after impact, Composite Structures 203 (2018) 648-658.

[11] S. I. Thorsson, S. P. Sringeri, A. M. Waas, B. P. Justusson, M. Rassaian, Experimental investigation of composite laminates subject to lowvelocity edge-on impact and compression after impact, Composite Structures 186 (2018) 335-346.

[12] S. I. Thorsson, A. M. Waas, M. Rassaian, Low-velocity impact predictions of composite laminates using a continuum shell based modeling approach part b: Bvid impact and compression after impact, International Journal of Solids and Structures 155 (2018) 201-212.

[13] S. I. Thorsson, A. M. Waas, M. Rassaian, Low-velocity impact predictions of composite laminates using a continuum shell based modeling approach part a: Impact study, International Journal of Solids and Structures 155 (2018) 185-200.

[14] J. Zhou, P. Wen, S. Wang, Finite element analysis of a modified progressive damage model for composite laminates under low-velocity impact, Composite Structures (2019) 111113.

[15] I. Lapczyk, J. A. Hurtado, Progressive damage modeling in fiberreinforced materials, Composites Part A: Applied Science and Manufacturing 38 (11) (2007) 2333-2341.

[16] M. V. Donadon, L. Iannucci, B. G. Falzon, J. M. Hodgkinson, S. F. M. de Almeida, A progressive failure model for composite laminates subjected to low velocity impact damage, Computers Structures 86 (11-12) (2008) 1232-1252.

[17] T. E. Tay, G. Liu, V. B. C. Tan, X. S. Sun, D. C. Pham, Progressive failure analysis of composites, Journal of Composite Materials 42 (18) (2008) 1921-1966.

[18] P. F. Liu, B. B. Liao, L. Y. Jia, X. Q. Peng, Finite element analysis of dynamic progressive failure of carbon fiber composite laminates under low velocity impact, Composite Structures 149 (2016) 408-422.
[19] C. Zhang, N. Li, W. Wang, W. K. Binienda, H. Fang, Progressive damage simulation of triaxially braided composite using a $3 \mathrm{~d}$ meso-scale finite element model, Composite Structures 125 (2015) 104-116.

[20] F. Guo-dong, L. Jun, W. Bao-lai, Progressive damage and nonlinear analysis of $3 \mathrm{~d}$ four-directional braided composites under unidirectional tension, Composite Structures 89 (1) (2009) 126-133.

[21] C.-S. Lee, J.-H. Kim, S.-k. Kim, D.-M. Ryu, J.-M. Lee, Initial and progressive failure analyses for composite laminates using puck failure criterion and damage-coupled finite element method, Composite Structures 121 (2015) 406-419.

[22] Z. Zhao, H. Dang, C. Zhang, G. J. Yun, Y. Li, A multi-scale modeling framework for impact damage simulation of triaxially braided composites, Composites Part A: Applied Science and Manufacturing 110 (2018) $113-125$.

[23] Z. Zhao, P. Liu, C. Chen, C. Zhang, Y. Li, Modeling the transverse tensile and compressive failure behavior of triaxially braided composites, Composites Science and Technology 172 (2019) 96-107.

[24] A. P. K. Joseph, P. Davidson, A. M. Waas, Progressive damage and failure analysis of single lap shear and double lap shear bolted joints, Composites Part A: Applied Science and Manufacturing 113 (2018) 264-274.

[25] F. Chang, K. Chang, A progressive damage model for laminated composites containing stress concentrations, Composite Materials 21 (1987) 832-855.

[26] J. Hou, N. petrinic, C. Ruiz, S. Hallett, Prediction of impact damage in composite plates, Composites Science and Technology 60 (2000) 273281.

[27] J. Hou, N. Petrinic, C. Ruiz, A delamination criterion for laminated composites under low-velocity impact, Composites Science and Technology 61 (2001) 2069-2074

[28] Z. Hashin, A.Rotem, A fatigue failure criterion for fiber reinforced materials, Composite Materials 7 (1973) 448-464.

[29] Z. Hashin, Failure criteria for unidirectional fiber composites, Journal of Applied Mechanics 47 (2) (1980) 329-334

[30] A. Puck, H. Schurmann, Failure analysis of frp laminates by means of physically based phenomenological models, Composites Science and Technology 62 (2002) 1633-1662.

[31] J. Zhang, X. Zhang, An efficient approach for predicting low-velocity impact force and damage in composite laminates, Composite Structures 130 (2015) 85-94

[32] J. Zhang, X. Zhang, Simulating low-velocity impact induced delamination in composites by a quasi-static load model with surface-based cohesive contact, Composite Structures 125 (2015) 51-57.

[33] Y. Shi, T. Swait, C. Soutis, Modelling damage evolution in composite laminates subjected to low velocity impact, Composite Structures 94 (9) (2012) 2902-2913.

[34] J. Pederson, Finite element analysis of carbon fiber composite ripping using abaqus, Thesis (2008).

[35] D. Feng, F. Aymerich, Finite element modelling of damage induced by low-velocity impact on composite laminates, Composite Structures 108 (2014) 161-171

[36] P. P. Camanho, C. G. Davila, M. F. de Moura, Numerical simulation of mixed-mode progressive delamination in composite materials, Journal of Composite Materials 37 (16) (2003) 1415-1438.

[37] A. Riccio, A. De Luca, G. Di Felice, F. Caputo, Modelling the simulation of impact induced damage onset and evolution in composites, Composites Part B: Engineering 66 (2014) 340-347.

[38] V. Antonucci, F. Caputo, P. Ferraro, A. Langella, V. Lopresto, V. Pagliarulo, M. R. Ricciardi, A. Riccio, C. Toscano, Low velocity impact response of carbon fiber laminates fabricated by pulsed infusion: A review of damage investigation and semi-empirical models validation, Progress in Aerospace Sciences 81 (2016) 26-40.

[39] D. Chen, G. Sun, M. Meng, G. Li, Q. Li, Residual crashworthiness of cfrp structures with pre-impact damage - an experimental and numerical study, International Journal of Mechanical Sciences 149 (2018) 122-135.

[40] A. Riccio, R. Ricchiuto, S. Saputo, A. Raimondo, F. Caputo, V. Antonucci, V. Lopresto, Impact behaviour of omega stiffened composite panels, Progress in Aerospace Sciences 81 (2016) 41-48.

[41] D. Chen, Q. Luo, M. Meng, G. Sun, Low velocity impact behavior of interlayer hybrid composite laminates with carbon/glass/basalt fibres, Composites Part B: Engineering 176 (2019) 107191.

[42] A. P. K. Joseph, P. Davidson, A. M. Waas, Open hole and filled hole 
progressive damage and failure analysis of composite laminates with a countersunk hole, Composite Structures 203 (2018) 523-538.

[43] N. Nguyen, A. M. Waas, A novel mixed-mode cohesive formulation for crack growth analysis, Composite Structures 156 (2016) 253-262.

[44] C. Bouvet, B. Castanié, M. Bizeul, J.-J. Barrau, Low velocity impact modelling in laminate composite panels with discrete interface elements, International Journal of Solids and Structures 46 (14-15) (2009) 28092821

[45] N. Hongkarnjanakul, C. Bouvet, S. Rivallant, Validation of low velocity impact modelling on different stacking sequences of cfrp laminates and influence of fibre failure, Composite Structures 106 (2013) 549-559.

[46] Y. Shi, C. Pinna, C. Soutis, Interface cohesive elements to model matrix crack evolution in composite laminates, Applied Composite Materials 21 (1) (2013) 57-70.

[47] Y. Shi, C. Pinna, C. Soutis, Modelling impact damage in composite laminates: A simulation of intra- and inter-laminar cracking, Composite Structures 114 (2014) 10-19.

[48] S. H. Diaz Valdes, C. Soutis, Real-time nondestructive evaluation of fiber composite laminates using low-frequency lamb waves, The Journal of the Acoustical Society of America 111 (5) (2002) 2026-2033.

[49] G. Duvant, J. L. Lions, Inequalities in mechanics and physics, Vol. 219,
Springer Science \& Business Media, 2012

[50] Z. P. Bažant, B. H. Oh, Crack band theory for fracture of concrete, Matériaux et construction 16 (3) (1983) 155-177.

[51] R. Krueger, Virtual crack closure technique: history, approach, and applications, Applied Mechanics Reviews 57 (2) (2004) 109-143.

[52] M. L. Benzeggagh, M. Kenane, Measurement of mixed-mode delamination fracture toughness of unidirectional glass/epoxy composites with mixed-mode bending apparatus, Composites science and technology 56 (4) (1996) 439-449.

[53] Standard test method for measuring the damage resistance of a fiberreinforced polymer matrix composite to a drop-weight impact event, ASTM International, 2007.

[54] G. A. Schoeppner, S. Abrate, Delamination threshold loads for low velocity impact on composite laminates, Composites: Part A 31 (2000) 903915.

[55] M. A. Meyers, Dynamic behavior of materials, John wiley \& sons, 1994.

[56] Z. Shen, Characterisation of low velocity impact response in composite laminates, Thesis (2015).

[57] X. Lou, H. Cai, P. Yu, F. Jiao, X. Han, Failure analysis of composite laminate under low-velocity impact based on micromechanics of failure, Composite Structures 163 (2017) 238-247. 